\title{
ABANDONO ESCOLAR: REPERCUSSÕES SÓCIO-ECONÓMICAS NA REGIÃO CENTRO. ALGUMAS REFLEXÕES
}

LuCília CAETANO $^{1}$

\begin{abstract}
Resumo - Embora a escolaridade da população tenha francamente melhorado nas últimas décadas, os indicadores posicionam Portugal na cauda da Europa. Em causa está o abandono escolar precoce conjugado com o insucesso escolar.

Em consequência desta situação, Portugal é o País da UE que apresenta uma maior percentagem de trabalhadores com baixo nível de escolaridade. Neste âmbito a Região Centro revela uma situação pouco favorável. Com efeito, apesar da evolução positiva observada entre os mais jovens, não deixa de ser inquietante o facto de apenas $27,1 \%$ (61,8\% na UE) dos jovens activos com idades compreendidas entre os 15 e os 24 anos terem concluído o Ensino secundário ou Cursos Profissionais e $3 \%$ não concluírem sequer o $1 .^{\circ}$ Ciclo do Ensino Básico.

Esta situação condiciona inevitavelmente a qualidade do capital humano constituindo um obstáculo ao crescimento económico e ao aumento de produtividade e de competitividade do tecido produtivo.
\end{abstract}

Palavras-chave: Habilitações escolares da população, abandono escolar, nível de escolaridade da população activa, Região Centro.

Abstract - School DRop-out: SOCIO-ECONOMIC REPERCUSSIONS In the PORTUGUeSE CENTRE REgion. SOME CONSIDERATIONS. Although the educational level of the population has improved considerably over the last decades, Portugal still lags far behind the other European countries. Premature school drop-out, along with high retention rates, appear to be the main reasons for this. Consequently, Portugal is the EU country with the largest percentage of workers with low educational levels, and the Central Region of Portugal is the one with the least favourable record. Indeed, in spite of the positive evolution registered among the youngest, it is still disturbing to find that only $27.1 \%$ (61.8\% in the EU) of the economically active young people between the ages of 15 and 24 finished their secondary education or pursued vocational training and that $3 \%$ did not even finish the first cycle of basic education. This situation inevitably hinders the formation of human capital, prevents the expansion of productivity and curbs the competitiveness of the productive fabric, as well as economic growth.

Key words: academic qualifications of the population, school drop-out, level of education of the workers, centre region of Portugal.

1 Professora Catedrática aposentada da Faculdade de Letras da Universidade de Coimbra. 


\begin{abstract}
Résumé - L'ABANDON SCOLAIRE: SES RÉPERCUSSIONS SOCIO-ÉCONOMIQUES DANS LA RÉGION-CENTRE. Bien que la scolarisation ait fortement progressé au cours des dernières décennies, le Portugal se trouve encore en queue des États européens, à cause de l'abandon précoce des études et de l'échec scolaire. C'est pourquoi c'est le pays de l'UE qui présente le plus fort pourcentage de travailleurs avec bas niveau de scolarisation. La Région-Centre est mal située à cet égard. Bien qu'une évolution positive s'y observe entre les plus jeunes, il est inquiétant de constater qu'à peine $27,1 \%$ des jeunes actifs, entre 15 et 24 ans, y aient terminé l'Enseignement secondaire ou un Cours professionnel (contre 61,8\% dans l'UE) et que $3 \%$ d'entre eux n'ont même pas achevé le $1^{\text {er }}$ cycle de l'Enseignement élémentaire. Cette situation, qui conditionne la qualité du capital humain, fait obstacle à la croissance économique et à l'augmentation de la productivité et de la compétitivité économiques.
\end{abstract}

Mots-clés: qualification scolaire de la population, abandon scolaire, niveau de scolarité de la population active, Région-Centre du Portugal.

\title{
I. INTRODUÇÃO
}

A modernização de uma sociedade passa por níveis sustentados de desenvolvimento económico e social.

Por sua vez, o desenvolvimento económico depende da capacidade de progresso técnico, o da organização e das relações entre os diferentes níveis das instituições públicas e privadas (incluindo firmas e famílias), das fontes de financiamento, e fundamentalmente da qualidade da população.

Efectivamente a qualidade do factor humano é um recurso para o território, na medida em que tem efeitos sobre a dinâmica da economia e é essencial para atingir competitividade.

Em suma, informação, conhecimento, capacidade de aprendizagem, de adaptação e inovação assumem importância crescente na obtenção de vantagens competitivas.

Acresce que, no processo de formação dos recursos humanos, o território deve assumir um papel activo.

Nesta perspectiva impõe-se que as estratégias de formação tenham base endógena mobilizando os actores intervenientes no processo: estabelecimentos escolares, empresas e a comunidade em geral.

A relação entre a economia e a educação vem sendo evidenciada desde os economistas clássicos, porém ganha impulso a partir da segunda metade do século vinte, através da teoria do Capital Humano.

Esta teoria, formalizada por Theodore W. Schultz no início dos anos 1960, destaca que a capacidade produtiva do indivíduo, para além dos factores materiais da produção, joga um papel decisivo no processo económico.

Todavia, para dispor e aumentar esta capacidade produtiva das pessoas, requerem-se investimentos em educação (MARGIOTTA et al., 1996).

De facto, para atingir níveis relevantes em todas as dimensões do desenvolvimento económico e social, a educação enfrenta o desafio de formar indivíduos 
competentes, quer dizer capazes de resolver os problemas com que se defrontam, quer como cidadãos, quer como agentes económicos.

Para além disto, tanto a educação em geral, como a formação técnico-profissional, em particular, são elementos essenciais para a elaboração de uma política de emprego.

Neste contexto, a educação deve contemplar o desenvolvimento de atitudes capazes de permitir manejar conhecimentos científicos e tecnológicos em permanente actualização, capacidades organizativas, interactivas, sociais, éticas e estéticas.

\section{NÍVEIS DE INSTRUÇÃO DA POPULAÇÃO}

De acordo com o EUROSTAT (dados relativos a 1999) apenas $22 \%$ da população, com idade compreendida entre os 25 e os 59 anos, completou o ensino secundário, ou seja a percentagem mais baixa da UE, enquanto a média europeia (UE-15) é $61,8 \%$. Porém a Dinamarca e Alemanha atingem cerca de $82 \%$.

Para os adultos jovens ( 25 a 29 anos de idade) a percentagem na UE-15 sobe para $71,4 \%$ (cerca de $90 \%$ na Dinamarca), ao passo que Portugal mantém o último lugar com $35,1 \%$.

Assim, os indicadores de escolaridade da população mostram que há ainda um longo caminho a percorrer para igualar as médias europeias, apesar da situação ter francamente melhorado nas últimas décadas (Quadro I).

No entanto, a despeito de instituída, em 1836, a obrigatoriedade da escolaridade primária (1. ${ }^{\circ}$ Ciclo do Ensino Básico), ainda hoje não foi cumprida em pleno. Disto é prova a constante taxa de analfabetismo (Quadro I).

Quadro I - Nível de instrução da população, 1950-2001 (\%)

Table I-Educational level of the population

\begin{tabular}{lcccc}
\hline & $\mathbf{1 9 5 0}(\mathbf{a})$ & $\mathbf{1 9 6 0 ( a )}$ & $\mathbf{1 9 9 1}$ & $\mathbf{2 0 0 1}$ \\
\hline Analfabetos & $40,3^{*}$ & $36,2^{*}$ & $11,0^{* *}$ & $9,0^{* *}$ \\
Sabem ler e escrever & 41,4 & 28,2 & - & - \\
Ensino Básico $\left(1 .^{\circ}\right.$ Ciclo) & 15,8 & 31,6 & 43,8 & 35,1 \\
Ensino Básico $\left(2 .^{\circ}\right.$ Ciclo) & - & - & 12,7 & 12,6 \\
Ensino Básico $\left(3 .^{\circ}\right.$ Ciclo) & - & - & - & 10,9 \\
Ensino Secundário & 1,9 & 3,2 & 19,5 & 15,7 \\
Ensino Médio & - & - & - & 0,8 \\
Ensino Superior & 0,6 & 0,8 & 6,3 & 10,8 \\
\hline
\end{tabular}

* População com mais de 7 anos de idade.

* População com mais de 10 anos de idade.

Fonte: (a) SILVA, M. (1991), p.29 e Censos da População, 1991 e 2001 (elaboração própria). 
Entretanto, a escolaridade básica obrigatória foi ampliada para 6 anos em 1964 (por Decreto-Lei n. ${ }^{\circ} 45810$ de 9 de Junho de 1964) e a partir de 1987 passou para 9 anos. Todavia, são numerosas as crianças que atingem a idade limite para frequentar o Ensino Básico (15 anos), sem terem concluído os 3 Ciclos do Ensino Básico (Quadro II).

Quadro II - Taxas reais de escolarização, 1990/91 (\%)

Table II - Rates of actual school attendance, 1990/91 (\%)

\begin{tabular}{cccc}
\hline Escalão Etário & $\mathbf{1 .}^{\mathbf{0}}$ Ciclo & $\mathbf{2 .}^{\mathbf{o}}$ Ciclo & $\mathbf{3 .}^{\mathbf{0}}$ Ciclo \\
\hline $6-9$ & 96,0 & & \\
$10-11$ & & 70,9 & \\
$12-14$ & & & 64,6 \\
\hline
\end{tabular}

Fonte: Sebastião, J. (1998): 316.

Ora se atendermos que nenhum país do mundo se tornou competitivo sem uma superior qualidade dos seus recursos humanos, a presente situação compromete qualquer iniciativa de descolagem da cauda da Europa.

Para além disto, alastra, igualmente, o analfabetismo funcional: sabem ler e escrever, mas não dominam a interpretação linguística, o cálculo e a resolução dos problemas.

São disto exemplo as mais baixas classificações registadas, nos diferentes níveis escolares, em provas globais de Língua Portuguesa e Matemática.

Uma situação que revela, entre outras causas, falhas no Sistema de Ensino, já que a «instrução básica deve potenciar, prioritariamente, qualificações em literacia e aritmética..., e, por sua vez o nível educacional superior deve favorecer a capacidade para transferir actividades não rotineiras» (MALECKI, 1991: 367).

Carnevale, Gainer e Meltzer (1988, citados por Malecki, 1991: 367) estabelecem a hierarquia da qualificação básica académica, para além do saber ler, escrever e da aritmética, em:

1 - saber como aprender,

2 - competência para ler, escrever e conhecimentos de informática,

3 - comunicação oral e compreensão do que se escuta,

4 - adaptabilidade, criatividade e resolução de problemas,

5 - gestão pessoal, auto-estima, motivação e objectivos de desenvolvimento pessoal e profissional,

6 - eficácia de grupo, qualificações interpessoais, capacidade de negociação e trabalho de grupo,

7 - eficácia organizacional e liderança. 
Acresce que, a educação e programas de treinamento constituem a base do sistema pelo qual o capital humano duma nação é preservado e aumentado (Johnston e PACKer, 1987; Porter, 1990, citados por MALECKI, 1991: 368).

O nível de ensino atingido pela população das diferentes Regióes de Portugal Continental, apesar de revelar algumas assimetrias regionais (Quadro III), enferma de uma similitude negativa. Apenas se destaca a Região de Lisboa e Vale do Tejo ao registar uma situação mais favorável, ultrapassando a média nacional.

Neste universo, a população da Região Centro detém insuficiente escolarização, embora tenha sofrido uma evolução positiva na década 1991/2001.

Quadro III - Nível de Ensino atingido* (\%) pela população, por Regiões (1991/2001)

Table III - Highest educational level reached* (\%), by Region (1991/2001)

\begin{tabular}{|c|c|c|c|c|c|c|c|c|c|c|}
\hline \multirow{3}{*}{ Regiões } & \multicolumn{6}{|c|}{ Ensino Básico } & \multirow{2}{*}{\multicolumn{2}{|c|}{$\begin{array}{l}\text { Médio e } \\
\text { Superior }\end{array}$}} & \multirow{2}{*}{\multicolumn{2}{|c|}{$\begin{array}{c}\text { Taxa } \\
\text { Analfabetismo }\end{array}$}} \\
\hline & \multicolumn{2}{|c|}{$1 .^{\circ}$ Ciclo } & \multicolumn{2}{|c|}{$2 .^{\circ}$ Ciclo } & \multicolumn{2}{|c|}{ 3. ${ }^{\circ}$ Ciclo e Sec. } & & & & \\
\hline & 1991 & 2001 & 1991 & 2001 & 1991 & 2001 & 1991 & 2001 & 1991 & 2001 \\
\hline Norte & 46,8 & 37,6 & 15,0 & 15,1 & 15,7 & 23,8 & 5,1 & 9,5 & 9,9 & 8,3 \\
\hline Centro & 46,2 & 38,1 & 12,2 & 12,3 & 16,5 & 24,3 & 5,1 & 9,8 & 14,0 & 10,9 \\
\hline L.V.T & 39,5 & 28,5 & 10,9 & 9,5 & 25,9 & 32,8 & 9,3 & 17,7 & 8,2 & 5,7 \\
\hline Alentejo & 41,8 & 36,2 & 10,9 & 11,2 & 16,8 & 24,5 & 3,8 & 8,3 & 21,8 & 15,9 \\
\hline Algarve & 43,3 & 34,5 & 10,2 & 10,9 & 21,9 & 29,8 & 4,5 & 10,0 & 14,2 & 10,4 \\
\hline Continente & 43,7 & 35,0 & 12,6 & 12,5 & 19,7 & 26,6 & 6,5 & 11,7 & 10,9 & 8,9 \\
\hline
\end{tabular}

* Foram efectuados ajustamentos em função das alterações ocorridas nos níveis de Ensino, no período intercensitário.

Fonte: Censos da População, 1991 e 2001, INE (elaboração própria).

Porém, internamente as desigualdades são assaz acentuadas, como mostra o Quadro IV.

Há uma evidente dicotomia entre o litoral e o interior e neste entre as NUTs III mais industrializadas e as basicamente rurais, marcadas ainda pelo analfabetismo de uma percentagem apreciável da população (Pinhal Interior Sul com 19,8\% e Beira Interior Sul com 17,4\%).

Apesar de o analfabetismo atingir dominantemente a população idosa destes territórios envelhecidos, não deixa de ser preocupante o facto de o nível de ensino alcançado pela generalidade da população não ir além do $1 .^{\circ}$ Ciclo de Ensino Básico (a 4. ${ }^{\mathrm{a}}$ Classe do Ensino Primário, cfr. Quadro IV). 
Quadro IV - Nível de Ensino atingido (\%), pela população da Região Centro, 2001

Table IV-Highest educational level reached* by the population of the Central Portugal Region (\%), 2001

\begin{tabular}{|c|c|c|c|c|c|c|c|c|c|}
\hline \multirow[b]{2}{*}{ NUTsIII } & \multirow[b]{2}{*}{ Nenhum } & \multicolumn{3}{|c|}{ Básico } & \multirow[b]{2}{*}{ Sec. } & \multirow[b]{2}{*}{ Médio } & \multirow[b]{2}{*}{ Sup. } & \multicolumn{2}{|c|}{ Taxa Analf. } \\
\hline & & $\begin{array}{c}1^{\circ} \\
\text { Ciclo }\end{array}$ & $\begin{array}{c}2 .^{\circ} \\
\text { Ciclo }\end{array}$ & $\begin{array}{c}3^{\circ} \\
\text { Ciclo }\end{array}$ & & & & 1991 & 2001 \\
\hline Região Centro* & 15,5 & 38,1 & 12,3 & 10,5 & 13,8 & 0,6 & 9,2 & 14,0 & 10,9 \\
\hline Baixo Vouga & 12,7 & 37,5 & 14,2 & 11,3 & 14,0 & 0,6 & 9,7 & 8,9 & 7,1 \\
\hline Baixo Mondego & 13,8 & 34,2 & 11,0 & 10,0 & 15,1 & 0,9 & 15,0 & 11,2 & 9,4 \\
\hline Pinhal Litoral & 15,7 & 35,7 & 12,5 & 11,9 & 15,2 & 0,5 & 8,5 & 13,2 & 10,1 \\
\hline Pinhal Int. Norte & 17,4 & 44,0 & 12,3 & 9,4 & 11,1 & 0,4 & 5,4 & 16,7 & 13,1 \\
\hline Dão-Lafões & 16,0 & 40,3 & 13,3 & 9,8 & 11,8 & 0,5 & 8,3 & 14,7 & 11,6 \\
\hline Pinhal Int. Sul & 22,3 & 43,2 & 10,9 & 8,4 & 10,1 & 0,3 & 4,8 & 24,5 & 19,8 \\
\hline Serra Estrela & 15,7 & 46,1 & 10,6 & 9,3 & 10,7 & 0,5 & 7,1 & 15,8 & 12,8 \\
\hline Beira Int. Norte & 17,9 & 41,6 & 10,3 & 9,2 & 11,7 & 0,6 & 8,7 & 18,0 & 14,9 \\
\hline Beira Int. Sul & 20,1 & 37,6 & 10,2 & 9,4 & 12,6 & 0,6 & 9,5 & 22,7 & 17,4 \\
\hline Cova Beira & 17,5 & 37,8 & 12,3 & 10,5 & 13,1 & 0,5 & 8,3 & 18,8 & 14,0 \\
\hline
\end{tabular}

* Inclui as NUTs III Oeste e Médio Tejo

Fonte: Censo da População 2001 e Anuário Estatístico da Região Centro, INE (elaboração própria).

As assimetrias observadas a nível da escolaridade da população não só reflectem, como reforçam, as desigualdades económicas e sociais na Região Centro.

Por outro lado, verifica-se que a aplicação das recentes Políticas da Educação não atingiu os objectivos delineados, uma vez que muitas crianças abandonam precocemente o Sistema de Ensino sem terem concluído o nível de escolaridade obrigatória ( $3 .^{\circ}$ Ciclo do Ensino Básico).

\section{ABANDONO ESCOLAR PRECOCE}

Na sequência dos resultados encontrados para o nível de ensino atingido pela população resulta evidente que o abandono escolar precoce é elevado.

Efectivamente, como mostra o Quadro V a saída precoce do Sistema de Ensino ocorre mais significativamente nos $1 .^{\circ}$ e $3 .^{\circ}$ Ciclos do Ensino Básico e no Secundário. 
Quadro V - Abandono Escolar, segundo os níveis de Ensino, 2001 (\%)

Table V-School drop-out by level of schooling, 2001 (\%)

\begin{tabular}{|c|c|c|c|c|c|c|}
\hline \multirow{2}{*}{ NUTsIII } & \multicolumn{3}{|c|}{ Ensino Básico } & \multirow{2}{*}{ Secundário } & \multirow{2}{*}{ Médio } & \multirow{2}{*}{ Superior } \\
\hline & $1 .^{\circ}$ Ciclo & 2. ${ }^{\circ}$ Ciclo & 3. ${ }^{\circ}$ Ciclo & & & \\
\hline Baixo Vouga & 21,8 & 15,2 & 26,5 & 34,4 & 13,1 & 8,0 \\
\hline Baixo Mondego & 24,3 & 17,5 & 25,4 & 32,4 & 13,1 & 7,0 \\
\hline Pinhal Litoral & 23,6 & 16,8 & 28,2 & 34,0 & 12,6 & 7,5 \\
\hline Pinhal Int. N. & 26,9 & 15,5 & 24,2 & 30,1 & 11,3 & 6,6 \\
\hline Dão-Lafões & 25,2 & 13,0 & 22,4 & 29,6 & 11,7 & 6,0 \\
\hline Pinhal Int. Sul & 26,3 & 15,0 & 20,5 & 26,2 & 5,3 & 7,0 \\
\hline Serra Estrela & 26,2 & 14,9 & 22,8 & 29,1 & 9,8 & 5,6 \\
\hline Beira Int. Norte & 25,4 & 16,1 & 21,4 & 28,7 & 9,5 & 6,9 \\
\hline Beira Int. Sul & 24,2 & 18,1 & 24,2 & 30,8 & 14,7 & 7,5 \\
\hline Cova Beira & 20,5 & 16,1 & 26,2 & 31,4 & 8,6 & 6,3 \\
\hline Região Centro & 23,7 & 16,2 & 25,4 & 32,4 & 12,8 & 7,3 \\
\hline Portugal & 20,5 & 17,2 & 25,1 & 32,6 & 16,5 & 0,9 \\
\hline
\end{tabular}

Fonte: Censo da População, 2001, INE, Lisboa (elaboração própria).

O abandono escolar registado no $1 .^{\circ}$ Ciclo de Ensino Básico é merecedor de reflexão e intervenção urgente.

O abandono escolar atravessa toda a Região Centro. No entanto, as causas divergem entre o litoral e o interior e entre os territórios mais industrializados e os rurais. Se para os primeiros o apelo do trabalho é a causa principal (obter um emprego não qualificado e /ou informal no tecido produtivo é relativamente fácil para os jovens), para os segundos são as dificuldades económicas das famílias, a cultura e a desmotivação pela Escola em geral, acrescida das distâncias a vencer para frequentar as aulas. De facto, o despovoamento das NUTs III rurais e montanhosas obriga a um reordenamento da rede escolar e consequente encerramento de escolas do $1 .{ }^{\circ}$ Ciclo do Ensino Básico.

Estes valores reflectem, igualmente, o insucesso escolar. «As taxas de insucesso escolar atingem $65,5 \%$ no $2 .^{\circ}$ ano de escolaridade e $50 \%$ no $4 .^{\circ}$ ano (no meio rural profundo).

No $3 .^{\circ}$ Ciclo as reprovações elevam-se a $30,7 \%$ no $7 .^{\circ}$ ano de escolaridade, $37,2 \%$ no $8 .^{\circ}$ ano e $26,7 \%$ no $9 .^{\circ}$ ano. Para concluir a escolaridade de 3 anos deste Curso Geral os alunos necessitam, em média, de 5 anos e meio» (ExPRESSO, Jornal, 1987: 26R-29R).

Segundo inquérito lançado (sob nossa orientação, no âmbito do Seminário Científico) por Professores Estagiários em Escolas E.B 2 e 3 da Região Centro (interior e litoral) onde funcionaram núcleos de Estágio em Geografia, nos anos lectivos 1998/99 e 1999/2000, foram identificadas, pelos alunos, as seguintes razões para não continuarem a estudar:

- vontade própria, 
- já estar cansado de estudar,

- estar na hora de tentar a independência,

- ser difícil ingressar no ensino superior,

- dificuldades financeiras (para alunos oriundos de famílias economicamente carenciadas).

Uma vez fora da Escola, o desejo do jovem é começar a trabalhar e apenas os provenientes de uma classe média e média alta consideram importante fazer um curso de formação profissional.

À questão 'A Escola é um lugar agradável?', a percentagem dos alunos que respondem negativamente é significativa:

$-15 \%$ dos alunos do $8 .^{\circ}$ ano e $50 \%$ no caso de alunos do $9 .^{\circ}$ ano.

Esta percentagem desce a partir do $10 .^{\circ}$ ano $\left(11 \%\right.$ e $5 \%$ no $11 .^{\circ}$ ano) para voltar a subir para os alunos do $12 .^{\circ}$ ano $(23 \%)$.

À questão "Gosta de estudar?», a percentagem de respostas negativas é deveras elevada.

Chega a atingir $60 \%$ entre os alunos do $9 .^{\circ}$ ano (a média atinge $24 \%$ ), $43 \%$ no $10 .^{\circ}$ ano, $10 \%$ no $11 .^{\circ}$ ano e $36 \%$ no $12 .^{\circ}$ ano.

À questão 'Pretende ingressar numa Universidade?', mais uma vez há uma significativa percentagem de alunos que responde negativamente:

$-45 \%$ dos alunos do $9 .^{\circ}$ ano, $43 \%$ dos do $10 .^{\circ}$ ano, baixa para $15 \%$ entre os alunos do $11 .^{\circ}$ ano, para voltar a subir entre os alunos do $12 .^{\circ}$ ano (33\%).

São resultados que impõem, portanto, uma visão integrada do problema onde a sociedade é interveniente central (a escola, a família, o tecido económico e as instituições).

\section{ESCOLARIZAÇÃO E DESENVOLVIMENTO}

A escolarização tem por objectivo proporcionar conhecimentos, capacidades e atitudes que constituam uma base sólida e geral (não específica) permitindo aos educandos aceder a outros níveis educativos. Ou seja:

- dotar os indivíduos da capacidade para que possam actualizar as aprendizagens permanentemente, durante o curso de suas vidas,

- desenvolver nos educandos capacidades para processar e assimilar informação, 
- promover a abertura para uma cultura laboral e científico-tecnológica e/ou a reorientação e reconversão técnico-profissional.

A qualidade do trabalho é o factor fundamental da produção na teoria económica. Efectivamente, os «clusters» territoriais desenvolvem-se em função do conhecimento e das qualificações profissionais.

Escolarização e indústria são exemplo da relação entre a ciência e a tecnologia (BHALLA, 1979; STEWART, 1978; citados por MALECKI, 1991: 138).

A capacidade tecnológica, proporcionada pela concentração de cientistas, engenheiros e pessoal técnico, traduz-se na liderança tecnológica de regiões ou nações nas quais foi gerada tecnologia e conhecimento (STEWART, 1978; MALECKI, 1991).

Acresce que a indústria de alta tecnologia põe em evidência o contraste entre trabalho técnico e trabalho não qualificado utilizado na produção estandardizada (Batten, 1985; Hall e Markussen, 1985; Malecki, 1991). Para além disto, aquela exige da parte do profissional uma aprendizagem contínua.

Por sua vez, BIRCH (1987, e 1989, citado por MALECKI, 1991: 332) refere, entre os factores que promovem o empreendorismo, os recursos educacionais, particularmente o ensino superior e a investigação.

A Comissão Europeia identifica a baixa qualificação da mão-de-obra portuguesa como o principal obstáculo ao crescimento económico e ao aumento da produtividade em Portugal.

«Para reduzir a escassez de mão-de-obra qualificada é fundamental melhorar a transição da escola para o trabalho, mas também aumentar o controlo de qualidade dos programas educacionais e de formação»(GARRIDO, 1997: 2-3).

Portugal, em 2000, apresentava uma elevada percentagem de trabalhadores com baixo nível de habilitações escolares (51,1\%: no caso dos homens e 40,0\% no sector feminino. Uma divergência que resulta de o abandono escolar precoce afectar mais os rapazes (Quadro VI). Por outro lado, apenas 4,1\% dos homens e $5,4 \%$ das mulheres trabalhadoras haviam realizado uma formação profissional.

Quadro VI - Grau de habilitação escolar atingido pelos activos, a nível nacional (2000)

Table VI-Educational level of the economically active population at the national level (2000)

\begin{tabular}{lcc}
\hline & Homens (\%) & Mulheres (\%) \\
\hline Inferior ao básico & 51,1 & 40,0 \\
Básico (9. ${ }^{\circ}$ ano) & 19,7 & 23,7 \\
Secundário & 16,9 & 23,4 \\
Superior não universitário & 4,1 & 5,6 \\
Superior universitário & 8,2 & 7,3 \\
\hline
\end{tabular}

Fonte: Condição de Trabalho em Portugal. Continente 2000, Ed. DETEFP, Ministério do Trabalho e da Solidariedade, p. 23. 
No entanto, as empresas preferencialmente recrutam pessoal que comece a produzir de imediato, não necessitando de formação profissional que represente encargos para a empresa. Deste modo, os jovens que tiveram uma formação profissional complementar beneficiam de melhores condições no mercado de trabalho do que aqueles que seguiram apenas o ensino obrigatório.

Com efeito, a nível da formação profissional contínua (como forma de valorização do seu pessoal) apenas 13,1\% das empresas portuguesas (dominando as com mais de 100 trabalhadores) a promoveram, enquanto a média europeia é 57\% (87\% na Dinamarca). Desta beneficiaram 28,7\% dos activos inquiridos (Condição de Trabalho em Portugal. Continente 2000, Ed. DETEFP, Ministério do Trabalho e da Solidariedade, p.26 e 27).

Na Região Centro os activos com nível de Ensino Secundário e de Escolas Profissionais representam, no global, $14,4 \%$. No entanto, entre os jovens com idades compreendidas entre os 20 e os 24 anos sobe para 30,1\% (Quadro VII).

Comparando o nível de Ensino atingido pelos trabalhadores nos escalóes etários considerados, verifica-se uma evolução positiva, entre os mais jovens, apesar do elevado abandono escolar. Prevalece ainda a frequência escolar obrigatória como habilitação escolar (2. ${ }^{\circ}$ Ciclo do Ensino Básico). Os jovens com idades comprendidas entre os 15 e os 19 anos, contudo, têm, maioritariamente, completado o $3 .^{\circ}$ Ciclo.

Porém, este facto pode resultar de uma selecção, por parte do empregador, dos profissionais com nível de escolaridade mais elevado.

Todavia, não deixa de ser preocupante o facto de 3,8\% dos jovens com idades compreendidas entre os 15 e os 19 anos não possuir sequer o $1 .^{\circ}$ Ciclo do Ensino Básico.

A modernização do tecido produtivo deixa de fora os trabalhadores não qualificados, com os empregadores privilegiando profissionais de nível intermédio e quadros superiores licenciados, dominando as novas tecnologias.

Todavia, a reestruturação do tecido económico tradicional ainda não atingiu o nível suficiente para absorver os jovens com formação de nível científico e técnico superior.

Desemprego e difícil acesso ao $1 .^{\circ}$ emprego afectam, ainda, os jovens licenciados.

Para além disto, a difusão da inovação no tecido económico não é uniforme na Região Centro. Apesar das disparidades de desenvolvimento esta ainda é dominada por um tecido económico de base tradicional (Quadro VIII).

Os nichos de excelência tecnológica (indústria e serviços produtivos) emergem precisamente onde se concentram os recursos humanos com formação escolar de nível superior (Baixo Vouga-Aveiro, Baixo Mondego - Coimbra e Pinhal Litoral - Leiria/Marinha Grande). 
Quadro VII - Trabalhadores, por conta de outrém, segundo a habilitação escolar, por grupo etário (\%), na Região Centro (2001)

Table VII-Employed workers by educational level and age group (\%), in the Central Portugal Region (2001)

\begin{tabular}{|c|c|c|c|c|c|c|c|}
\hline \multirow{2}{*}{$\begin{array}{l}\text { Grupos } \\
\text { Etários }\end{array}$} & \multirow{2}{*}{$\begin{array}{l}\text { Inferior } \\
1 .^{\circ} \text { Ciclo }\end{array}$} & \multicolumn{3}{|c|}{ Ensino Básico } & \multirow{2}{*}{$\begin{array}{l}\text { Sec. e } \\
\text { Prof. }\end{array}$} & \multirow{2}{*}{ Bachar. } & \multirow{2}{*}{ Lic. } \\
\hline & & $1 .^{\circ}$ Ciclo & $2 .^{\circ}$ Ciclo & $3 .^{\circ}$ Ciclo & & & \\
\hline $15-19$ & 3,8 & 6,7 & 24,4 & 49,7 & 15,4 & - & - \\
\hline $20-24$ & 2,8 & 7,5 & 26,5 & 23,2 & 30,1 & 2,2 & 7,7 \\
\hline $25-34$ & 3,6 & 15,5 & 29,5 & 10,6 & 20,8 & 5,3 & 14,7 \\
\hline $35-44$ & 5,5 & 36,7 & 21,4 & 9,1 & 14,8 & 3,5 & 9,0 \\
\hline $45-54$ & 8,1 & 59,2 & 7,8 & 6,6 & 8,6 & 3,4 & 6,3 \\
\hline $55-64$ & 23,5 & 57,4 & 5,0 & 4,5 & 4,4 & 1,7 & 3,5 \\
\hline $65 \mathrm{e}+$ & 36,7 & 45,1 & 3,7 & 4,6 & 4,1 & 1,4 & 4,4 \\
\hline Média & 8,5 & 36,8 & 18,1 & 10,0 & 14,4 & 3,5 & 8,7 \\
\hline
\end{tabular}

Fonte: Censo da População, 2001, INE (elaboração própria).

Quadro VIII - Trabalhadores por conta de outrém, segundo o sector de actividade*, $1999(\%)$

Table VIII - Employed workers by activity sector*, 1999 (\%)

\begin{tabular}{ccccccc}
\hline \multirow{2}{*}{ Distritos } & \multirow{2}{*}{ Primário } & \multirow{2}{*}{ Secundário } & \multicolumn{2}{c}{ Indústria (intensidade R\&D)* } & \multicolumn{2}{c}{ Terciário } \\
\cline { 4 - 6 } & & & Média e Alta & Baixa & Total & Produtivo \\
\hline Aveiro & 1,5 & 69,2 & 21,7 & 78,3 & 29,3 & 35,0 \\
Cast. B. & 5,8 & 54,1 & 12,4 & 87,6 & 40,1 & 33,3 \\
Coimbra & 2,2 & 45,0 & 15,0 & 85,0 & 52,8 & 40,7 \\
Guarda & 3,0 & 53,9 & 21,1 & 78,9 & 43,1 & 32,0 \\
Leiria & 3,1 & 56,2 & 23,1 & 76,9 & 40,7 & 34,8 \\
Viseu & 4,3 & 51,4 & 17,7 & 82,3 & 44,3 & 35,2 \\
Reg.Centro & $\mathbf{2 , 7}$ & $\mathbf{5 8 , 5}$ & $\mathbf{2 0 , 2}$ & $\mathbf{7 9 , 8}$ & $\mathbf{3 8 , 8}$ & $\mathbf{3 6 , 0}$ \\
Continente & $\mathbf{2 , 6}$ & $\mathbf{4 5 , 0}$ & $\mathbf{2 0 , 3}$ & $\mathbf{7 9 , 7}$ & $\mathbf{5 2 , 4}$ & $\mathbf{4 5 , 5}$ \\
\hline
\end{tabular}

* Classificação adaptada de OCDE, citada por MALECKI (1991): 61 e 175.

Fonte: DETEFP, Ministério do Trabalho e da Solidariedade, Quadros de Pessoal, Indicadores Globais, 1995-2000 (elaboração própria).

\section{CONCLUSÃO}

Apesar de a Escola ser, por excelência, o espaço de formação global e específica do indivíduo, análises ao sistema educativo português têm identificado os seguintes pontos fracos:

- elevado peso de analfabetismo,

- abandono escolar precoce,

- fragilidade do ensino técnico e tecnológico. 
No conjunto do sistema educativo o abandono escolar precoce assume no ensino secundário a maior expressão, constituindo um dos mais preocupantes factores de descriminação social e cultural entre as novas gerações.

$\mathrm{Na}$ generalidade o fracasso escolar significa fracasso pessoal e social, já que a escolarização é também importante condicionante no sistema de estratificação da sociedade.

Para além disto a educação é condição primordial do desenvolvimento com equidade.

Numa sociedade em que a democratização do ensino visa assegurar a toda a população um período obrigatório de educação básica, que se prolonga até à idade em que seja legalmente possível trabalhar, sublinha-se que a qualidade do trabalho (qualificação e flexibilidade) está alicerçada na escolaridade realizada até aos 18 anos.

Neste contexto, o abandono escolar precoce, ao comprometer a formação e a qualificação dos trabalhadores, reflecte-se no processo de desenvolvimento sócio-económico e de competitividade dos territórios.

\section{BIBLIOGRAFIA}

ABreu, M. V., et al. (1983) - Da prevenção do insucesso escolar ao desenvolvimento interpessoal. Revista Portuguesa de Pedagogia, Ano XVII: 143-170.

Almeida, J. F. et al. (1992)-Exclusão social. Factores e tipos de pobreza em Portugal, Ed. Celta, Oeiras.

ANJo, M. D. P. (1995) - Insucesso escolar: dupla exclusão - o saber e a praxis em saúde. Intervenção Social, V(11/12): 129-152.

ARroteia, J. C. (1989) - A inserção da 2. a geração de emigrantes no sistema educativo português. Desenvolvimento Regional, Boletim da CCRC, 28/29: 107-143.

ARroteia, J. C. (1990)-Enseignement supérieur et développement régional au Portugal. Revue Géographique des Pyrénées et du Sud-Ouest, 61(1): 139-155.

BEL, M. (1998) - La formation profissionnelle et technique est inscrite dans le territoire. Espace et société, 92/93: 127-147.

Benavente, A., et. al. (1996) - Renunciar à Escola. O abandono escolar no Ensino Básico, Ed. Fim de Século, Lisboa.

CAeIro, A. (1988) - Insucesso Escolar. In EXPRESSO, Jornal, Ed.7 de Maio.

CAETANo, L. (1999) - Emprego e desemprego na Região Centro, num contexto de mudança. Actas do $V$ Encontro Nacional da APDR «Emprego e Desenvolvimento Regional», col. APDR, Ed. IERU, Coimbra, vol.I: $145-160$.

CAETANO, L. (orientação) (1998-2000)-Inquérito executado por professores estagiários em Escolas E.B. 2 e 3, Anos Lectivos 1998/1999 e 1999/2000, no âmbito do Seminário Científico da Formação de Estagiários, sob o Tema «Insucesso Escolar e Expectativas Profissionais».

CAETANO, L. (2001) - Child labour, the reserve of economic globalization in peripheral regions. In Jussila, H. et. al., Globalization and marginality in geographical space, Ed. Ashgate: 267-278. 
Caetano, L. (2002) -A pobreza na Região Centro. In CAetano, L. (coord.), Território, Globalização e Trajectórias de Desenvolvimento, Ed. CEG, Coimbra: 321-357.

CAMAcho, A. (2000) - Uma abordagem sistémica da intervenção social no domínio da relação escolafamília-comunidade. Intervenção Social, 21: 99-110.

CAPucha, L. et al. (1998) - Grupos desfavorecidos face ao emprego - Tipologias e quadro básico de medidas recomendáveis. Estudos e Análises, Ed. Observatório do Emprego e Formação Profissional, Lisboa, n. ${ }^{\circ} 8$.

Detefp, Ministério do Trabalho E da Solidariedade (2000)-Quadros de Pessoal, Indicadores Globais, 1995-2000, em CD-ROM.

Eurostat Yearbook (2001) - The Statistical Guide to Europe, Ed. European Commission.

Expresso, Jornal (1987) - Insucesso Escolar. Ed.11 de Abril: 26R-29R.

FERRÃo, J. (1995) - Caracterização regional dos factores de abandono escolar e insucesso escolar, nos 2..$^{\circ}$ e.$^{\circ}$ Ciclos do Ensino Básico. Estudo de actualização. Ed. Ministério da Educação, Lisboa.

FERrão, J. et al. (2000) - Saída permatura do Sistema Educativo: Aspectos da situação, causas e perspectivas em termos de emprego e formação. Ed. Observatório do Emprego e Formação Profissional, Lisboa.

Fialho, J. A. (1998) - O trabalho infantil em Portugal: Caracterização social dos menores em idade escolar e suas famílias. Ed. Ministério do Trabalho e da Solidariedade, Lisboa.

Formosinho, J. O. (1986) - A intervenção da Escola no desenvolvimento sócio-moral. Desenvolvimento, Ed. Instituto de Estudos para o Desenvolvimento, Lisboa, 3: 61-74.

GARRIDO, H. (1997) - Educação e formação ameaçam crescimento. Relatório da Comissão Europeia sobre a economia portuguesa. Público (Jornal), Cad. Economia, 24 de Março: 2-3.

INE (2002) - Censo da População, 1991 e 2001, Lisboa.

INE (2002) - Anuário Estatístico da Região Centro. Lisboa.

JEAN, Y. (1995) - École et aménagement du territoire rural: quel avenir pour les petites structures scolaires et les communes rurales? Annales de Géographie, Ed. Armand Colin, 104 (583): 236-255.

LACERDA, A.; Ferreira, G. (1992) - As preferências dos jovens para o ingresso no ensino superior. Gestão e Desenvolvimento, Ed. Instituto Universitário de Desenvolvimento e Promoção Social, Universidade Católica Portuguesa, Centro Regional de Viseu, 1: 117-153.

Machado, F. L.; Costa, A. F. (1998) - Processos de uma modernidade inacabada. Mudanças estruturais e mobilidade social. In VIEgAs, J. M. L. e CostA, A.F. (org.), Portugal. Que modernidade, Ed. Celta, Oeiras: 17-44.

MALECKI, E. J. (1991)-Technology and economic development: the dynamics of local, regional, and national change, Ed. Longman.

Margiotta, E. D.; NAranjo, A. R. (1996) - La educación frente a las exigencias del desarrollo en America Latina. Signos Universitarios, XV (29): 71-96.

Ministério da Ciência e Tecnologia (1997) - Inquérito ao Potencial Científico e Tecnológico Nacional., MCT, Notícia 3, Maio de 1999.

Ministério do Trabalho e da Solidariedade (2000) - Condição de Trabalho em Portugal. Continente 2000, Ed. DETEFP, Ministério do Trabalho e da Solidariedade, Lisboa.

Muñız, B. M. (1989) - A família e o insucesso escolar, Ed. Porto Editora, Porto. 
PedRo, E. R. (1984) - Obstáculos ao sucesso escolar de crianças de meios populares - um projecto e algumas considerações. Desenvolvimento, n. ${ }^{\circ} 1$, Ed Instituto de Estudos para o Desenvolvimento, Lisboa: 57-66.

Pereira, F.; Martins, M. A. (1978) - O insucesso escolar e as suas explicações. Crítica de algumas teorias. Análise Psicológica, II (1): 33-56.

Pires, E. L. (1987) - Não há um, mas vários insucessos. Cadernos de Análise Social da Educação, Ed. Universidade do Minho, Braga: 11-15.

QuinTão, C. (1999) - Relações entre a Escola e o Mercado de Emprego Envolvente, Ed. Pórtico, Lisboa.

RoAzzi, A; Almeida, L. S. (1988) - Insucesso escolar: insucesso do aluno ou insucesso do sistema escolar? Revista Portuguesa da Educação, 1, Lisboa: 53-60.

Sebastião, J. (1998) - Os dilemas da escolaridade. Universalização, diversidade e inovação. In Viegas, J. M. L. e Costa, A.F. (org.), Portugal. Que modernidade, Ed. Celta, Oeiras: 311-327.

SILVA, M. (1991) - A pobreza infantil em Portugal. Ed. UNICEF.

STEсK, B. (1998)-L'exclusion ou le territoire du repli progressif. L'Information Géographique; 62(2): 66-71. 